Check for updates

Cite this: RSC Adv., 2017, 7, 47945

Received 7th June 2017

Accepted 28th September 2017

DOI: $10.1039 / c 7 r a 06399 g$

rsc.li/rsc-advances

\section{Effect of $p R i$ T-DNA genes and elicitation on morphology and phytoecdysteroid biosynthesis in Ajuga bracteosa hairy roots $\dagger$}

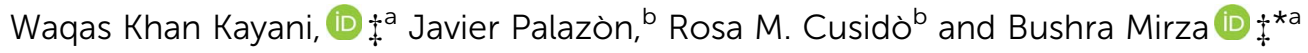

The medicinal plant Ajuga bracteosa is a rich source of biologically active and metabolism-enhancing phytoecdysteroids. Transgenic hairy roots from $A$. bracteosa were obtained by infection with Agrobacterium rhizogenes strains A4, LBA-9402 and ARqua1. The 59 selectively established and rolCpositive hairy root lines increased in size up to 6.6-fold (L42) after one month of in vitro culturing and produced a phytoecdysteroid content ranging from 69.3 to $4449 \mu \mathrm{g} \mathrm{g}^{-1}$ ( $\mathrm{L} 3$ and $\mathrm{A} 2$, respectively). The clones of these transgenic roots were maintained for successive subcultures on hormone-free medium to obtain a stabilized morphology. Hairy roots displayed four different morphologies: typical hairy root (THR) (59\%), callus-like (CM) (17\%), thick (TK) $(14 \%)$ and thin (TN) $(10 \%)$. The growth rate of the transgenic hairy root lines varied according to their morphology, with CM showing the highest rate (3.93-fold per month). However, THR exhibited the highest phytoecdysteroid content $\left(1538.5 \mu \mathrm{g} \mathrm{g}^{-1}\right.$ ). Considering the hairy root morphology in relation to the pRi TR-DNA genes, $100 \%$ of the hairy root lines harbored the mas1 and ags genes and 90\% of CM lines the aux1 gene. Strikingly, the clones with TK morphology were all positive for the TL- and TR-DNA genes. In contrast, $0 \%$ of TN clones harbored the aux1 and ags genes, and only $16.7 \%$ the mas1 gene. All CM and TK hairy roots were positive for the ags gene, while mas1 was present in all hairy root types except TN. As expected, all the root lines considered in this work were positive for the rol $C$ gene. Eleven hairy root lines displaying a high growth rate and phytoecdysteroid content were elicited with methyl jasmonate (MeJ) and coronatine (Cor). MeJ doubled the phytoecdysteroid content after 14 days of elicitation (8356 $\mu \mathrm{g} \mathrm{g}^{-1}$ in L2) compared with unelicited control hairy roots, and in in vitro-grown untransformed roots the increase was 5.6 -fold.

\section{Introduction}

Ajuga bracteosa (Lamiaceae) is a perennial medicinal herb of the sub-tropical and temperate regions of Kashmir, Bhutan, Pakistan, Afghanistan, China and Malaysia and highly used in folk medicine. ${ }^{1}$ Studies report that A. bracteosa alleviates liver fibrosis, ${ }^{2}$ possesses promising anti-inflammatory activity, ${ }^{3,4}$ and exhibits a dose-dependent inhibition of chronic arthritis in rats and analgesic effects in mice. ${ }^{3,6}$ Extracts of $A$. bracteosa are valuable antiplasmodial agents. ${ }^{7,8}$

Major compounds found in A. bracteosa are phytoecdysteroids, neo-clerodane diterpenoids, withanolides and iridoid glycosides. Phytoecdysteroids are structural analogs of the

${ }^{a}$ Department of Biochemistry, Faculty of Biological Sciences, Quaid-i-Azam University, Islamabad 45320, Pakistan. Fax: +92-51-90644050; Tel: +92-51-90643007

${ }^{b}$ Plant Physiology Laboratory, Faculty of Pharmacy, University of Barcelona, Avda Joan XXIII s/n, 08028 Barcelona, Spain. Fax: +34 9340290 43; Tel: +34 934020267

$\dagger$ Electronic supplementary information (ESI) available. See DOI: 10.1039/c7ra06399g

\$ Present address: Department of Plant Breeding, Swedish University of Agricultural Sciences, Växtskyddsvägen 1, SE-230 53 Alnarp, Sweden, bushramirza@qau.edu.pk. insect molting hormone ecdysone. In plants, these compounds are responsible for some physiological functions, while in mammals they have a huge variety of applications. Phytoecdysteroids increase protein-synthesizing processes, ${ }^{9}$ body mass $^{10}$ and blood protein content in rats, ${ }^{10}$ improve kidney functioning, ${ }^{11}$ suppress albuminuria, ${ }^{12}$ activate human lymphocytes, ${ }^{13}$ reduce lipid peroxidation, ${ }^{14}$ and increase the copulative function and improve sperm quality. ${ }^{15}$ They are neuroprotective, ${ }^{16}$ anti-hyperglycemic, ${ }^{17}$ anti-inflammatory, ${ }^{18}$ anti-diabetic ${ }^{19}$ and also possess antifungal and antibacterial activity. ${ }^{20}$

Hairy roots are a valuable biotechnological tool for the production of plant secondary metabolites due to their high productivity and growth rate, and genetic stability. ${ }^{21}$ Agrobacterium rhizogenes infect plants and generate hairy roots in response to the transfer and integration of DNA (T-DNA) from the large root-inducing agrobacterial plasmid (pRi) into the plant genome. ${ }^{22,23}$ Agropine type strains contain two T-DNA regions on the Ri plasmid known as TL-DNA and TR-DNA, which can be independently incorporated into the plant genome. ${ }^{22,24}$ The Ri TL-DNA carrying rolA, $B, C$ and $D$ genes is responsible for hairy root induction, ${ }^{24,25}$ while $\mathrm{Ri}$ TR-DNA 
possesses the genes responsible for opine biosynthesis, ${ }^{\mathbf{2 6}}$ as well as those involved in the additional route for the formation of indole acetic acid. The TR-region is also important in the determination of the hairy root morphology. ${ }^{27,28}$ Elicitation of hairy roots can further enhance the biosynthesis of valuable secondary metabolites. ${ }^{21}$

Phytoecdysteroid biosynthesis in A. reptans hairy roots was found to be closely related to their growth: in a root line (Ar-4) that increased in weight 230 -fold, the content of 20 -hydroxyecdysone (20-HE) increased 4 -fold after 45 days of culture. ${ }^{29}$ The regenerated plants from these hairy roots showed altered plant morphology ${ }^{30}$ but the same production of $20-\mathrm{HE}$ as in original root line. ${ }^{31}$ Hairy roots obtained from A. multiflora produced 10 times more 20-HE compared to the wild type. ${ }^{32}$ Moreover, elicitors are found to induce higher phytoecdysteroid biosynthesis in Spinacia oleracea plants..$^{33}$

To the best of our knowledge, in the present study, we evaluated for the first time the potential of transformed roots of A. bracteosa to produce phytoecdysteroids and the effect of elicitation. Moreover, the phenotypic effects of the integration of TR-DNA genes from A. rhizogenes into the hairy root genome were also investigated.

\section{Methods}

\section{Hairy roots cultures}

Hairy roots of Ajuga bracteosa were obtained by the transformation of the plant genome with three agropine Agrobacterium rhizogenes strains: A4, LBA-9402 and ARqua1 as described by Kayani, et al. ${ }^{34}$ Briefly, leaves with petioles at the proximal end were surface sterilized and infected with YEB (yeast extract and beef medium)-grown agrobacteria. Explants were infected with agrobacteria adhered to the surface of a sterile surgical blade. The inoculated leaf discs were placed on Schenk-Hildebrandt $(\mathrm{SH})$ medium $^{35}$ with a $\mathrm{pH}$ of 7 and containing $3 \%$ sucrose, $0.1 \%$ myoinositol and $0.8 \%$ phytagel at $27{ }^{\circ} \mathrm{C}$ in the dark. After a 2 day co-cultivation, the explants were shifted to new SH medium supplemented with claforan $(500 \mathrm{mg}$ $\mathrm{l}^{-1}$ ). The hairy roots were retained with the mother explants for 20-30 days, and were then excised and grown on optimized hormone-free half-strength Murashige and Skoog (MS) medium $^{36}$ (half-strength of salts) supplemented with $30 \mathrm{~g} \mathrm{l}^{-1}$ sucrose and solidified with $0.8 \%$ phytagel. Fifty nine hairy root clones were used to study growth and the phytoecdysteroid profile, and eleven of these (elite root clones in growth and production) were maintained in the growth room in darkness at $27^{\circ} \mathrm{C}$ and routinely subcultured every 2 weeks.

\section{Growth quotient}

To screen actively growing hairy roots, $200 \mathrm{mg}$ of fresh weight of root inoculum was cultured on half-strength media for one month. After the incubation period, each root line was harvested and its fresh weight measured. The growth quotient was obtained by dividing the hairy root fresh weight by the fresh weight of the inoculum. For the extraction of ecdysteroids, the harvested hairy roots were freeze-dried, weighed (dry weight) and ground to a fine powder. The powder was stored at $-20{ }^{\circ} \mathrm{C}$ until further processing.

\section{Treatment with elicitors}

Methyl jasmonate (MeJ) and coronatine (Cor) (Sigma-Aldrich, St. Louis, MO, USA) were added to the medium optimized for stable growth and production (half-strength MS) prior to inoculation. Both the elicitors were filter-sterilized $(0.22 \mu \mathrm{m}$ sterile PES filters, Millipore, Billerica, MA, USA) and added to the media just before pouring to make a final concentration of 100 $\mu \mathrm{M}$ MeJ and $1 \mu \mathrm{M}$ Cor. $200 \mathrm{mg}$ of fresh inoculum of each hairy root line was cultured for 14 and 21 days. Each treatment was conducted in triplicate, and to compare the effect of elicitors, control (unelicited) hairy roots were treated with $2.5 \mathrm{ml}$ ethanol (MeJ control). For analysis, three plates for each root line studied were harvested after 14 and 21 days of elicitation.

\section{Molecular analysis}

For the PCR analysis, genomic DNA was isolated from hairy roots and control roots (untransformed) by an optimized method $^{37}$ and its quantitative and qualitative parameters were checked by NanoDrop ND-1000 spectrophotometer (NanoDrop Technologies Wilmington, DE, USA). Integration of TL-DNA into the genome of hairy roots was confirmed by the PCR of the rolC gene. To ensure the hairy root clones were free from agrobacterial contamination, PCR was carried out to confirm the absence of the virD1 gene. TR-DNA integration into the hairy root genome was confirmed by the PCR analysis of aux1, mas1, and ags genes. The rolC and actin genes were used in the expression analysis by sq-RT-PCR. Total RNA was isolated with the TRIzol® Plus RNA Purification Kit (Life Technologies, Germany) following the manufacturer's instructions. cDNA was synthesized with SuperScript II reverse transcriptase (Invitrogen, Carlsbad CA) according to their instructions. PCR Master Mix (Life Technologies, Spain) was used for the PCR reaction in a thermocycler (Perkin-Elmer Gene Amp PCR System 9600, USA). The genes, primers, primer sequences and PCR conditions are described in Table 1. PCR conditions were fixed except for the annealing temperature. They consisted of: 5 minutes at $95{ }^{\circ} \mathrm{C}$; 35 cycles of $35 \mathrm{~s}$ at $95{ }^{\circ} \mathrm{C}, 35 \mathrm{~s}$ (primer annealing temperature given in Table 1), and $1 \mathrm{~min}$ at $70{ }^{\circ} \mathrm{C}$; and $10 \mathrm{~min}$ at $70{ }^{\circ} \mathrm{C}$. Amplified PCR products were resolved at 1.5 percent $(\mathrm{w} / \mathrm{v})$ agarose gel electrophoresis in TBE running buffer and visualized with UV-Trans illuminator (Life Technology, USA).

\section{Extraction of ecdysteroids}

The six ecdysteroids screened in the study were 20-hydroxyecdysone (20-HE), ajugalactone (AJL), sengosterone (SG), cyasterone (CY), polypodine (PoB) and makisterone A (MKA) (Fig. 1). ${ }^{3,34}$ For the ecdysteroid extraction, a previously optimized protocol $^{38}$ was followed with some modifications. ${ }^{34}$ In brief, powdered plant material $(\sim 500 \mathrm{mg})$ was extracted first with $10 \mathrm{ml}$ of methanol $(\mathrm{MeOH})$ two times and then the residue was extracted again with $85 \% \mathrm{MeOH}$ and both fractions $(100 \%$ $\mathrm{MeOH}$ and $85 \% \mathrm{MeOH}$ ) were mixed and dried. The resulting 
Table 1 Primers sequences of the genes used in the study ${ }^{a}$

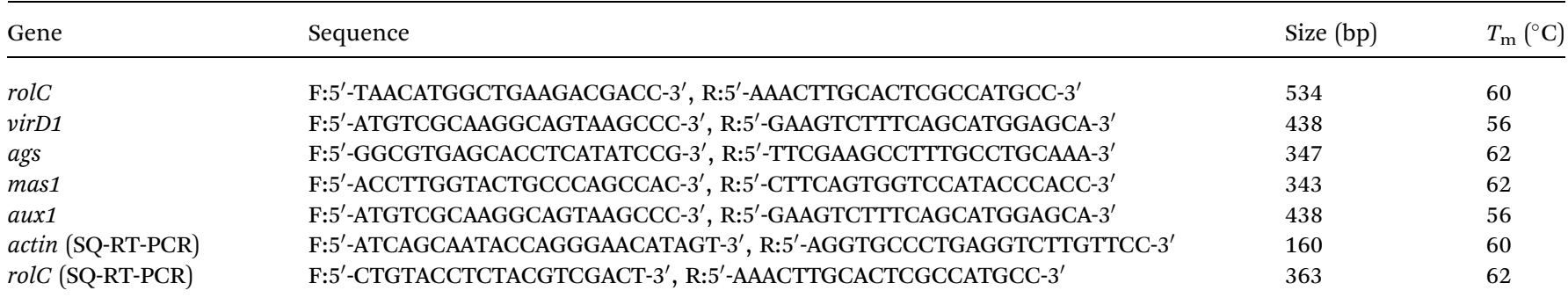

${ }^{a}$ PCR conditions were fixed except for annealing temperature. They were; 5 minutes $95{ }^{\circ} \mathrm{C}$, followed by 35 cycles of 35 seconds at $95{ }^{\circ} \mathrm{C}$, $35 \mathrm{~s}$ for primers annealing (temperature given in table), extension of $1 \mathrm{~min}$ at $70{ }^{\circ} \mathrm{C}$ and a final extension of $10 \mathrm{~min}$ at $70{ }^{\circ} \mathrm{C}$.<smiles>CC(C)(O)CC[C@H](O)[C@]1(C)CC[C@]2(O)C3CC(=O)[C@]4(C)C[C@@H](O)[C@@H](O)C[C@]4(C)[C@H]3CC[C@@]21C</smiles>

20-Hydroxyecdysone

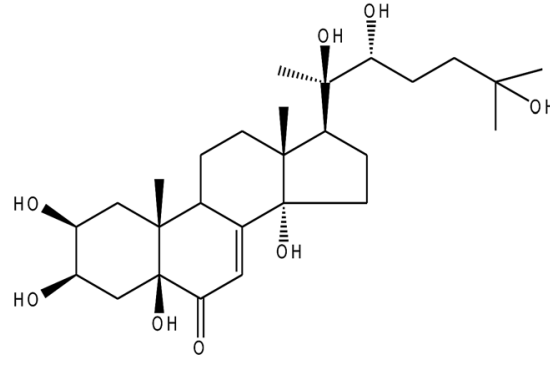

Polypodine B

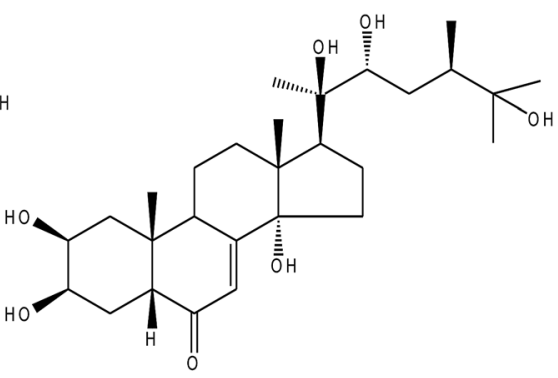

Makisterone A

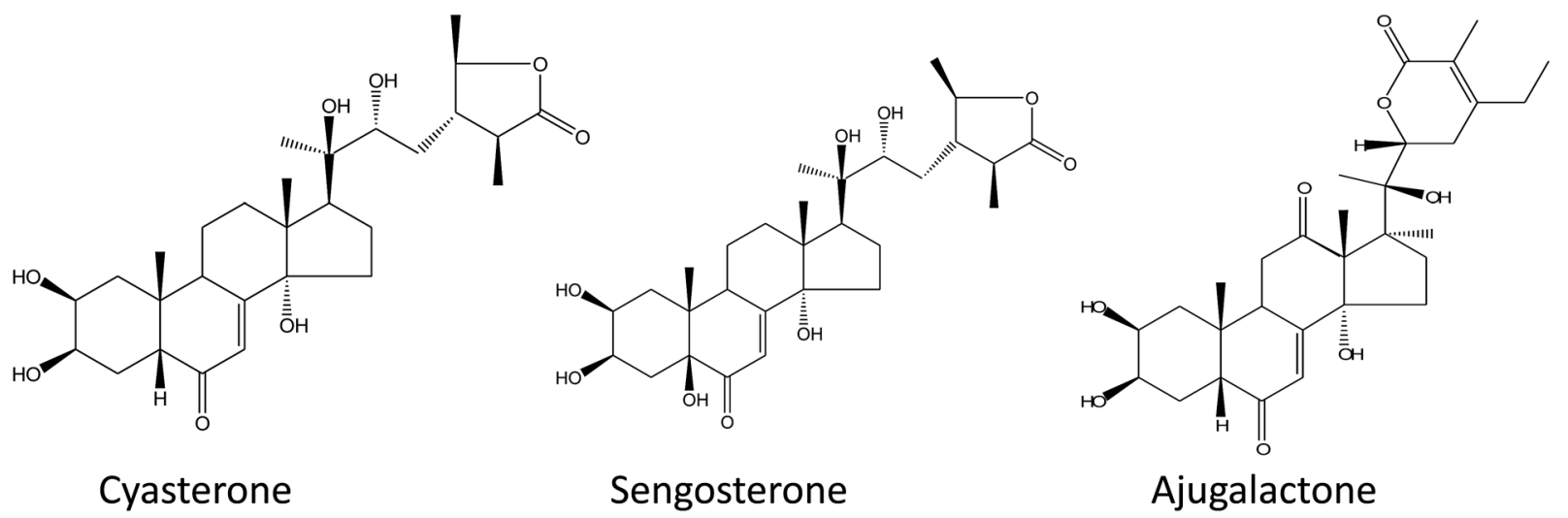

Fig. 1 Chemical structure of the used phytoecdysteroids standards.

pellet was resuspended in $85 \% \mathrm{MeOH}$, sonicated for $20 \mathrm{~min}$ and subjected to partial purification through previously activated/ equilibrated column cartridges (Strata C18-E, $55 \mu \mathrm{m}, 70 \mathrm{~A}$, Phenomenex, USA) with $85 \% \mathrm{MeOH}$. The filtrate obtained was dried, and the pellet was resuspended in $5 \mathrm{~mL}$ of $85 \% \mathrm{MeOH}$ and used for the HPLC injection.

\section{RP-HPLC analysis}

Analytical HPLC was performed according to already optimized protocols $^{34,39}$ and the mobile phases were water (A) and acetonitrile (B). The HPLC system, chromatographic column with its dimensions, injection volume, flow rate, the gradient program and the acquisition of UV spectra were same as described before. $^{34}$

\section{Results and discussion}

Phenotypic characterization and phytoecdysteroid content in transgenic roots

Transgenic roots were observed in the proximal end of $A$. bracteosa leaves infected with A. rhizogenes strains A4, LBA-9402 and ARqua1 carrying pRi within 9-12 days (Fig. 2a-d). The cultures were maintained for successive subcultures without changes in morphology. Among the selected hairy root lines, two were 

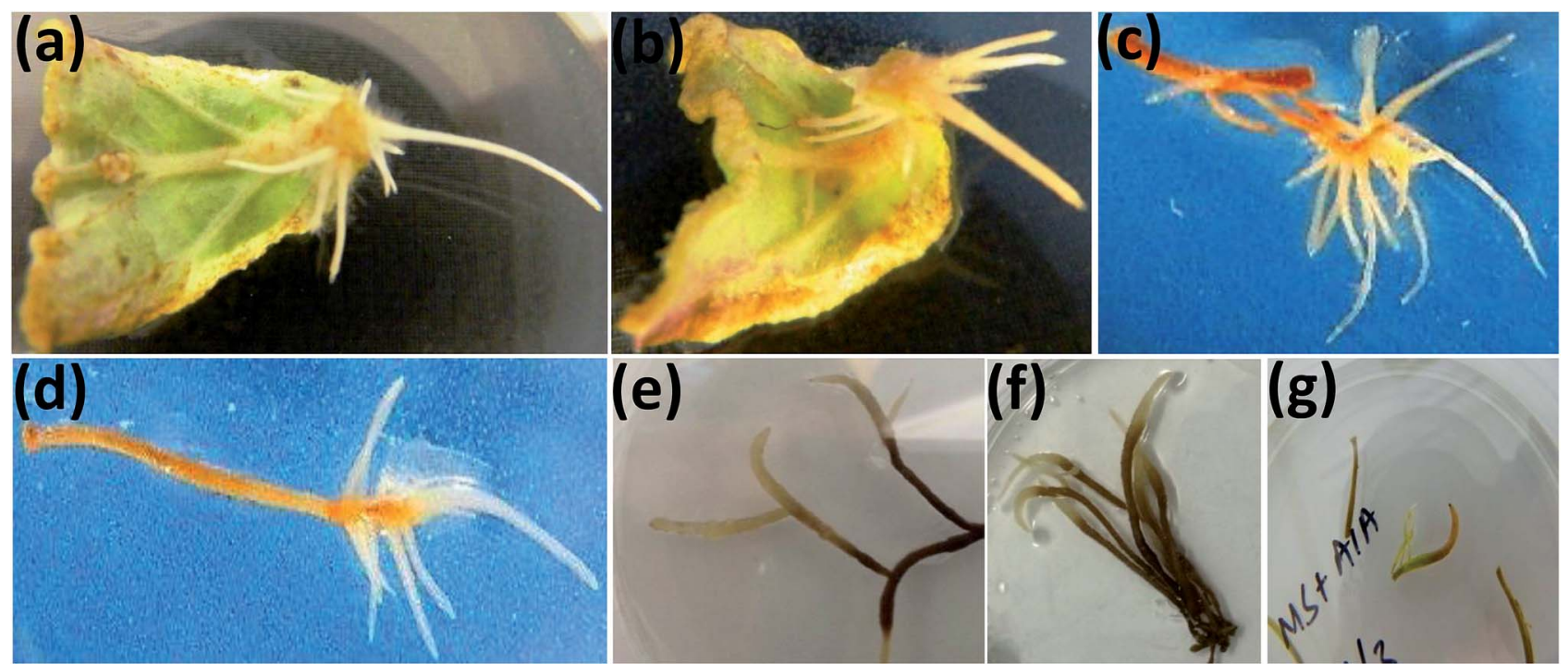

(h)
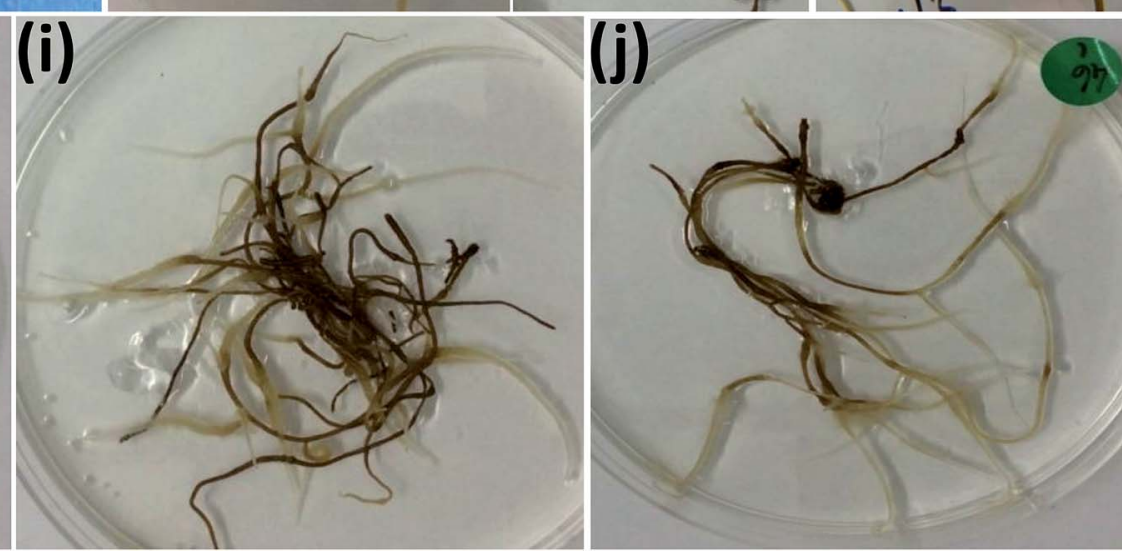

Fig. 2 Hairy roots induction and different morphologies. (a-d) Hairy root induction, (e-f) callus like morphology, (g) control in vitro grown untransformed roots, (h) transgenic hairy root with thick morphology, (i) transgenic hairy root with thin morphology, (j) typical transgenic hairy root.

obtained from the A4 strain (A1 and A2), while the others were obtained from the infection with the LBA-9402 strain (L1 to L42).

A variety of media (MS, B5 and SH with different combinations) was used for the optimization of hairy root induction, stabilization and steady growth (ESI Table $1 \dagger$ ). Among 1596 explants infected, LBA infected explants were 56.3\%. SH medium supported maximum hairy roots induction as 289 hairy roots ( $90 \%$ ramified) were produced from the only 60 infected explants. Moreover, unlike to that of MS or B5 media, the transgenic hairy roots were induced within a week over $\mathrm{SH}$ medium (ESI Table $2 \dagger$ ). Initially, half strength MS medium with IBA was found proliferating the hairy roots (ESI Table $3 \dagger$ ) but for the stable growth of well ramified hairy roots IBA was alleviated (ESI Table $4 \dagger$ ). Besides the media and hormones, the ex vitro source plants were found as the best explant source for hairy roots induction (ESI Table $5 \dagger$ ).

Only one hairy root line with moderate growing capacity was obtained from ARqua1 strain and named as AR1. The established hairy root cultures grew actively on hormone-free halfstrength medium, and showed four different morphologies

Table 2 Hairy root morphology and integration of T-DNA fragments of pRiA4 in hairy root genome ${ }^{a}$

\begin{tabular}{|c|c|c|c|c|c|c|c|c|}
\hline Root morphology & Incidence & Growth rate & PE content $\left(\mu \mathrm{g} \mathrm{g}^{-1} \mathrm{DW}\right)$ & virD1 & rolc & $\operatorname{aux1}$ & mas1 & ags \\
\hline THR & $58.62 \%$ & $3.277 \pm 0.32$ & $1538 \pm 48.2$ & $0 \%$ & $100 \%$ & $70.6 \%$ & $100 \%$ & $73.5 \%$ \\
\hline $\mathrm{CM}$ & $17.24 \%$ & $3.93 \pm 0.3$ & $1509.56 \pm 37.3$ & $0 \%$ & $100 \%$ & $90 \%$ & $100 \%$ & $100 \%$ \\
\hline $\mathrm{TN}$ & $10.34 \%$ & $2.35 \pm 0.52$ & $1202.3 \pm 63$ & $0 \%$ & $100 \%$ & $0.0 \%$ & $16.7 \%$ & $0.0 \%$ \\
\hline
\end{tabular}

${ }^{a}$ Growth capacity of transgenic clones of different root lines expressed as (harvested FW/inoculum FW) after 28 days of culture in hormone-free half strength MS medium. Each value is the average of 3 replicates. THR: typical hairy root, CM: callus like morphology, TK: hairy root with thick morphology, TN: hairy root with thin morphology, PE: phytoecdysteroid content. 

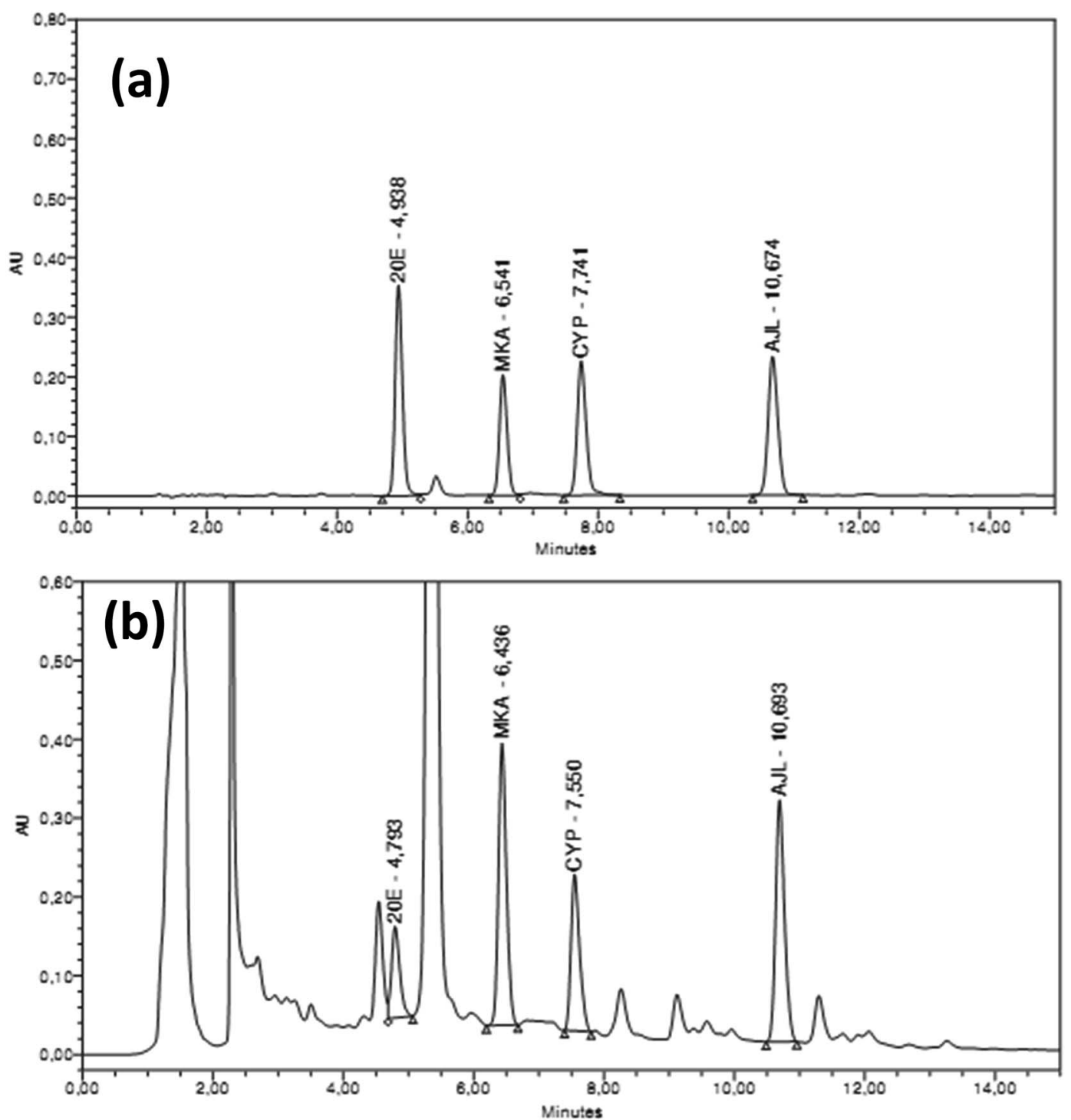

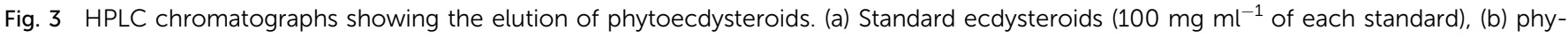
toecdysteroid elution pattern in one of the hairy root extract.

(Fig. 2e-j). Most of the hairy roots (59\%) exhibited typical hairy root morphology (THR), as described previously. ${ }^{40}$ Among the rest of the hairy root lines established, those with callus-like (CM), thick (TK) and thin (TN) morphology accounted for $17 \%, 14 \%$ and $10 \%$, respectively of the total (Table 2 ). All hairy root lines obtained were fast-growing, ramified and plagiotropic except those with CM, which were less ramified. The CM lines exhibited the capacity to dedifferentiate and produce callus tissue in hormone-free culture medium.

All the hairy root lines were subjected to HPLC analysis (Fig. 3) and growth rate measurements (Fig. 4). The growth rate of hairy roots (fresh weight harvested/fresh weight of inoculum) was found to be significantly high in 11 transgenic hairy root lines (Fig. 4a, Table 3). These fast-growing hairy root lines also possessed significantly high phytoecdysteroid contents, e.g. 4449 and $4122 \mu \mathrm{g} \mathrm{g}^{-1}$ DW accumulated by A2 and L1 hairy root lines, respectively (Fig. 4b). The growth rate of the transgenic hairy root lines varied according to their morphology (Fig. 4c).
After 30 days of culture, on average, CM hairy roots showed a higher growth rate (3.93 times) by producing $786 \mathrm{mg}$ of fresh weight in one month of culture than the other hairy root lines (Fig. 4c). However, THR showed more phytoecdysteroid content $\left(1538.48 \mu \mathrm{g} \mathrm{g}^{-1} \mathrm{DW}\right)$ than CM lines $\left(1509.56 \mu \mathrm{g} \mathrm{g}^{-1} \mathrm{DW}\right)$. The lowest phytoecdysteroid levels were found in TN and TK hairy roots (Table 2). A possible reason for the decrease in phytoecdysteroids in CM roots is the loss of organized tissue. Similarly, Mallol and coworkers found that ginsenoside production in Panax ginseng transgenic hairy roots with CM and THR morphology (levels almost the same) was significantly higher than in roots with thin morphology. ${ }^{27}$

\section{TL- and TR-DNA integration into the genome of transgenic hairy root lines}

We related the presence of T-DNA genes with the morphology and growth rate of transgenic hairy roots, and their 

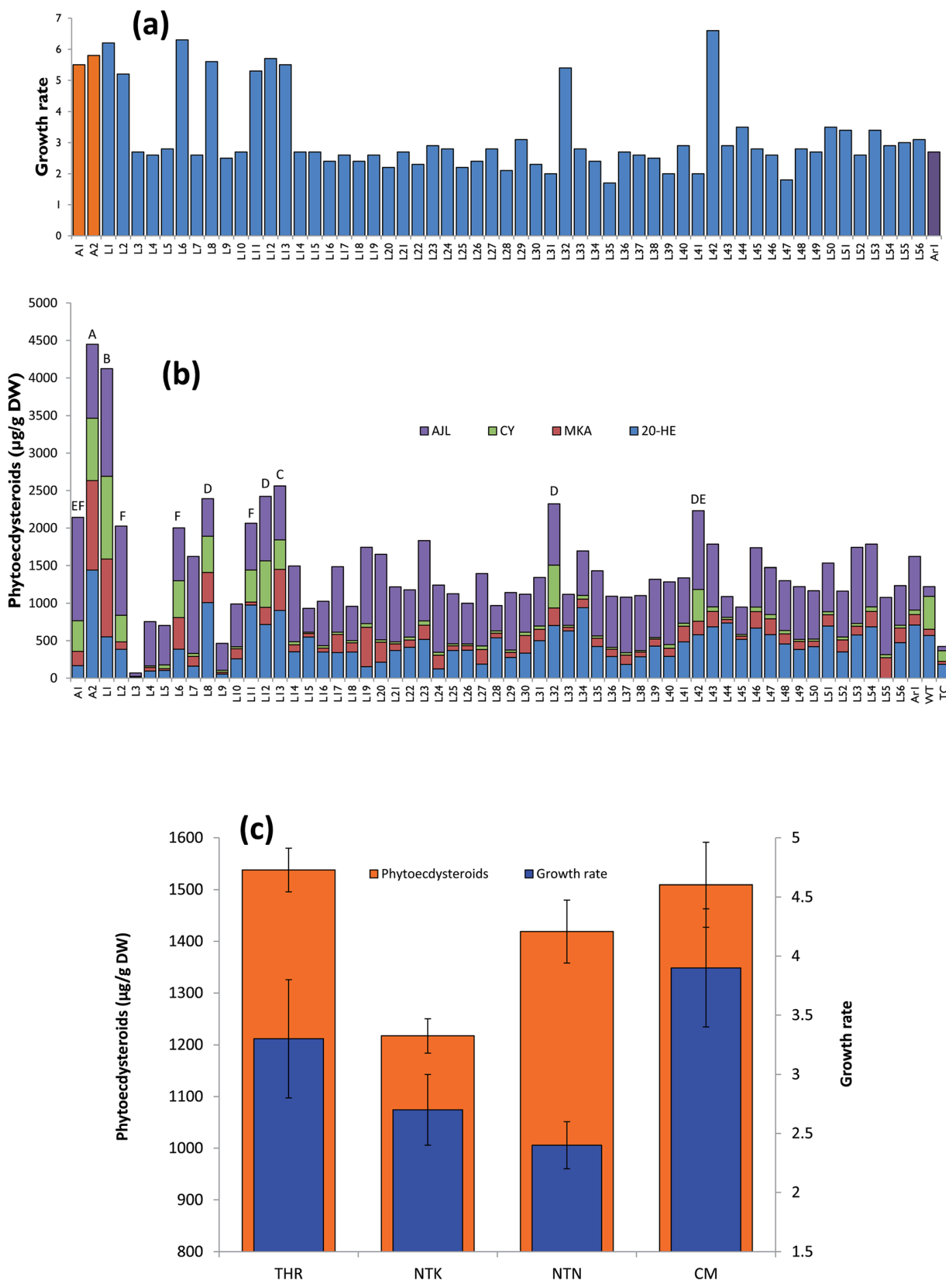

Fig. 4 Growth rate of hairy roots and production of phytoecdysteroids. (a) Growth rate of the transgenic hairy roots after one month of in vitro culturing, (b) phytoecdysteroid production by transgenic hairy roots, (c) growth rate and production of phytoecdysteroid contents compared with different hairy root morphologies. THR = typical hairy root, $\mathrm{CM}=$ callus like morphology, $\mathrm{TK}=$ normal hairy root with thick morphology, TN $=$ normal hairy root with thin morphology.

phytoecdysteroid content (ESI Table $6 \dagger$ ). Three TR-DNA genes of A. rhizogenes, aux1, ags and mas1, were screened along with the rolC gene located in the TL-DNA, which is a key gene responsible for hairy root development. The ags gene is involved in agropine biosynthesis, while the aux1 gene, as indicated previously, is considered to play an additional role in the formation of indole-3-acetic acid in transgenic material. ${ }^{\mathbf{4 1}}$ The mas 1 gene is involved in manopine biosynthesis. ${ }^{42}$

When comparing the different hairy root morphologies in relation with the genes of the pRi T-DNA, it was observed that $100 \%$ of the CM root lines harbored rolC, mas1 and ags genes, and $90 \%$ of the total hairy root lines established were positive 
Table 3 Analysis of variance (ANOVA) of transgenic hairy root lines using 2-factor complete randomized design ${ }^{a}$

\begin{tabular}{|c|c|c|c|c|c|}
\hline Source & $\mathrm{DF}$ & SS & MS & $F$-Value & $\begin{array}{l}P \\
\text { value }\end{array}$ \\
\hline Transgenic hairy roots & 58 & 22012543.866 & 379526.618 & 590.6268 & $* * *$ \\
\hline Ecdysteroids & 3 & 39953845.301 & 13317948.434 & 20725.6527 & $* * *$ \\
\hline $\begin{array}{l}\text { Transgenic hairy roots } \times \\
\text { phytoecdysteroids }\end{array}$ & 174 & 18722812.986 & 107602.373 & 167.4529 & $* * *$ \\
\hline Error & 472 & 303299.093 & 642.583 & & \\
\hline TOTAL & 707 & 80992501.246 & & & \\
\hline
\end{tabular}

${ }^{a}$ Coefficient of variation: $6.71 \%$. ANOVA of transgenic hairy root lines was done against 59 established root clones. DF, degree of freedom; SS, sum of squares; MS, means square. ${ }^{* *}$ means that the transgenic lines, phytoecdysteroids and their interaction is significant at $P<0.001$.

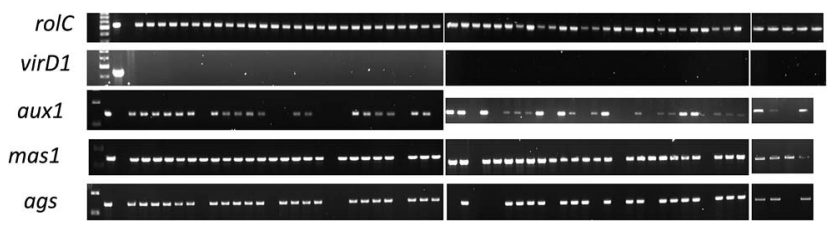

Fig. 5 PCR analysis of the selected genes to confirm their integration into the transgenic hairy roots' genome. First well contains ladder DNA second and third are positive and negative controls respectively while the rest of the samples are in accordance with the information provided in ESI Table $6 . \dagger$

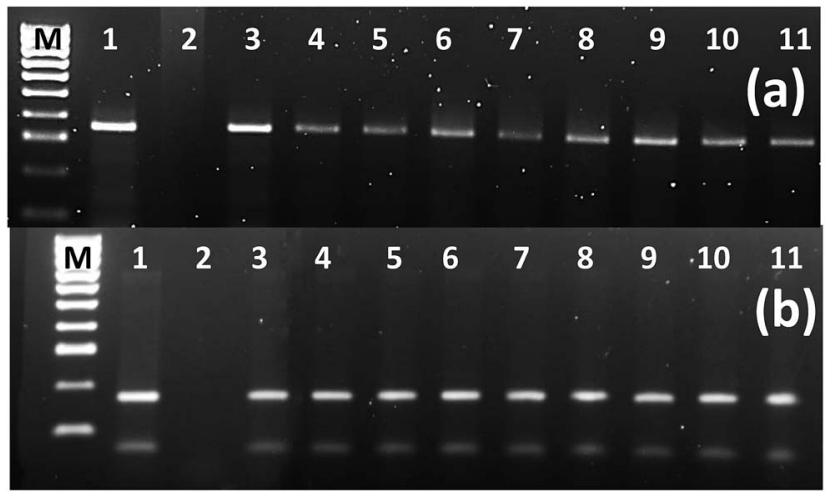

Fig. 6 Semiquantitative reverse transcriptase PCR analysis. (a) rolC gene in the selected high ecdysteroid yielding hairy root lines (363 bp). (b) actin as housekeeping gene (160 bp). $M$ = DNA ladder $100 \mathrm{bp}+, 1=$ positive control (in "a" it is PCR from the pA4 while in "b" it is plant gDNA), 2 = negative control (in "a" it is PCR from the gDNA of untransformed root while in " $b$ " it is PCR without DNA), 3-4 = hairy root lines $A 1$ and $A 2$ respectively which were obtained from infection of Agrobacterium rhizogenes A4 strain, 5-11 = L1, L2, L6, L8, L11, L12, $L 13, L 32$ and $L 42$ transgenic hairy root lines obtained from the infection of $A$. rhizogenes strain LBA-9402.

for aux1 (Fig. 5), which was not found in any of the TN roots (Table 2). A semi quantitative PCR analysis of the high phytoecdysteroid yielding transgenic hairy root lines has shown high rolC expression (Fig. 6). The role of the aux1 gene (to provide the transgenic cells with an additional source of auxins) is reflected in previous studies. ${ }^{43}$ Our findings are in accordance with previous work ${ }^{44}$ in which the provision of synthetic auxins (2,4-D) enhanced callus biomass and reduced alkaloid production. It is argued that the overproduction of auxins can drive the disorganization in the transgenic hairy root lines. ${ }^{45}$ Robins reported a complete loss of nicotine in the root clones of Nicotiana rustica treated with synthetic auxins. ${ }^{\mathbf{4 6}}$

Strikingly, the roots with TK morphology were $100 \%$ positive for the TL- and TR-DNA genes. In contrast, the TN roots showed $0 \%$ presence of the aux 1 and ags genes, and only $16.7 \%$ of them were positive for mas1 integration into their genome. The ags gene was present in all CM and TK hairy roots, while mas1 was present in all hairy root types except TN (Table 2 and ESI Table $1 \dagger$ ). In another study, $100 \%$ of CM hairy roots from tobacco, Duboisia hybrid and Datura metel Solanaceae plants exhibited insertion of the aux 1 gene. ${ }^{28}$ Less incorporation of TRDNA into transgenic hairy roots can be due to incomplete integration events. ${ }^{47}$ In a previous study, a constitutive $A$. tumefaciens strain carrying pRiA4TR (aux genes deleted) produced transgenic hairy roots with exactly the same morphology (no callogenesis) and alkaloid production as the transgenic roots obtained with the strain $\mathrm{A} 4 .^{28}$

\section{Effect of elicitors on phytoecdysteroid production in hairy root clones}

The hairy root lines (11 independent clones, Fig. $4 \mathrm{a}$ and b) exhibiting the highest growth rate and phytoecdysteroid content were selected to study the effect of elicitation with $\mathrm{MeJ}(100 \mu \mathrm{M})$ and Cor $(1 \mu \mathrm{M})$. Elicitation with $\mathrm{MeJ}$ was found to induce a maximum phytoecdysteroid content of $8356 \mu \mathrm{g} \mathrm{g}^{-1} \mathrm{DW}$ after 14 days in the L2 line, followed by L32, which produced $8066 \mu \mathrm{g}$ $\mathrm{g}^{-1}$ (Fig. 7a). In our study, elicitation with MeJ was more effective than with Cor. Moreover, higher phytoecdysteroid levels were obtained after 14 days of elicitation than 21 days.

Phytoecdysteroids are biosynthesized through the mevalonate pathway. In a previous study, $2-3.5 \%$ radiolabeled mevalonate (14C-MVA) was incorporated into the 20 -HE produced in spinach cultures after 24 hours. ${ }^{48}$ The key enzyme, 3-hydroxy-3methylglutaryl coenzyme A reductase (HMGR-CoA reductase), irreversibly converts HMG-CoA to MVA and is considered to be the rate-limiting factor in this pathway. ${ }^{49}$ The higher phytoecdysteroid content found in our elicited hairy root clones could be a result of a high expression of HMGR. Recently, an elicitor-responsive gene involved in 20 -HE production, encoding 3-hydroxy-3-methylglutaryl coenzyme A reductase (HMGR), was cloned in Cyanotis arachnoidea. The resulting enhanced 


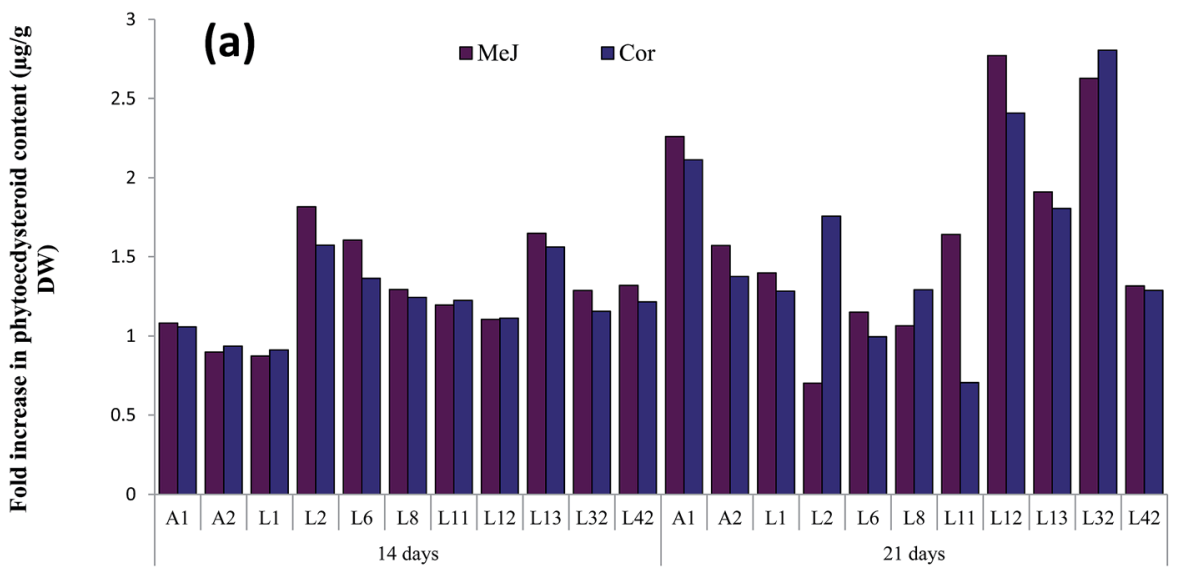

(b)

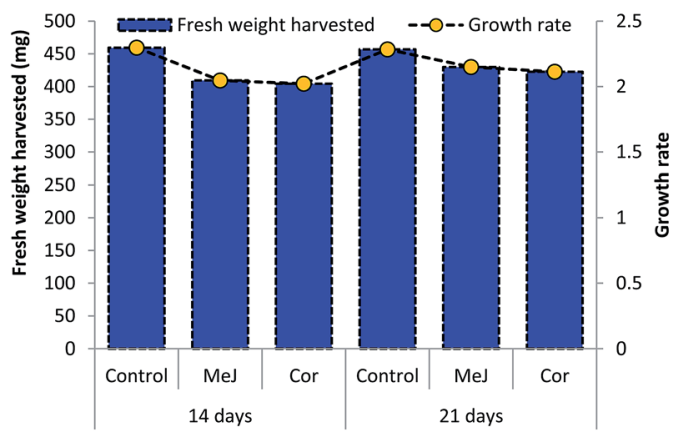

(c)

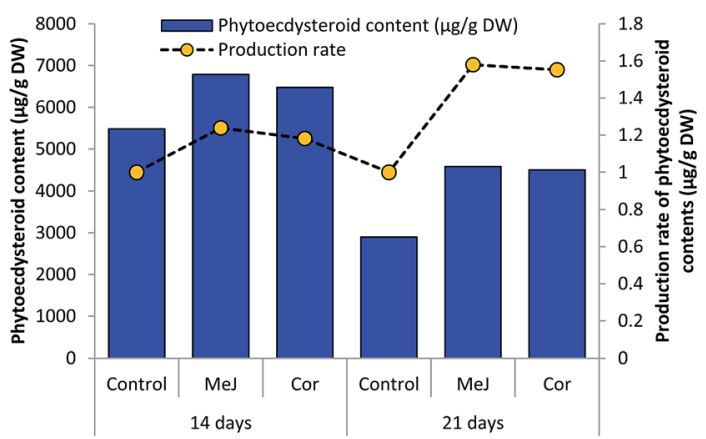

Fig. 7 Effect of $\mathrm{MeJ}$ and Cor on growth and production of phytoecdysteroids in transgenic hairy roots. (a) Production of phytoecdysteroid content in the selected transgenic hairy root lines in response to elicitation, (b) growth rate of elicited transgenic hairy root lines, (c) production rate of phytoecdysteroid content of elicited transgenic hairy root lines. MeJ: methyl jasmonate, Cor: coronatine.

biosynthesis of 20-HE in MeJ-treated cells and a correspondingly high expression of HMGR suggest that 20-HE biosynthesis may be the result of the up-regulation of CaHMGR expression..$^{50}$ HMGR provides mevalonate for the biosynthesis of 20-HE and other secondary metabolites. In another study, elicitation of Achyranthes bidentata cells with $0.6 \mathrm{mM}$ MeJ for 6 days produced 2.6-fold more 20-HE. ${ }^{51}$

The hairy root lines elicited for 21 days had a higher growth rate/ biomass than those treated for 14 days in comparison with their respective controls. The growth rate was determined after culturing the hairy root clones for one month on hormone-free medium. However, despite producing more biomass, 21 day-elicited roots had lower phytoecdysteroid levels and the treatment induced detrimental effects, since the hairy roots turned from yellow to brown and then dark brown, and ultimately died (Fig. 7b). The plasticity or tolerance of plants towards different chemicals varies according to species. For example, the treatment of spinach with MeJ induced $78 \%$ and $61 \%$ more 20 -HE concentration in roots and shoots, respectively, without affecting plant growth. ${ }^{33}$

On average, MeJ-treated hairy roots produced more phy-

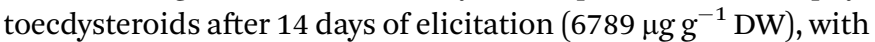
a 1.24-fold higher biomass production (Fig. 7c). In contrast, 21 days of elicitation with $\mathrm{MeJ}$ and Cor resulted in the average production of 4577 and $4498 \mu \mathrm{g} \mathrm{g}^{-1}$ DW of phytoecdysteroids, respectively, which was nevertheless 1.58 - and 1.55 -fold higher compared to the control. This reduction of phytoecdysteroid content after a longer elicitation period is in accordance with the experiments performed by Mangas and coworkers. The production of sterols in Centella asiatica, and Galphimia glauca increased after two weeks of MeJ treatment and then gradually declined during the third and fourth weeks. ${ }^{52}$ Decrease in phytoecdysteroid production could also be caused by a higher concentration of elicitors. In another Ajuga species, A. turkestanica, the 20-HE content increased 3-fold when the cell suspension culture was treated with $125 \mu \mathrm{M} \mathrm{MeJ}$ and it dramatically decreased when supplemented with $250 \mu \mathrm{M}$ MeJ compared to the control/untreated cultures. ${ }^{53}$

We report for the first time the biotechnologically enhanced production of phytoecdysteroids in A. bracteosa both via transformation and elicitation. pRi TR-DNA genes were found to play a significant role in the determination of the morphology of hairy roots. While those with callus-like morphology produced more biomass, typical transgenic hairy roots produced more phytoecdysteroids. Phytoecdysteroid levels were further enhanced by 14 days of MeJ elicitation. Based on these findings, it can be suggested that typical transgenic hairy roots treated with 14 days of MeJ elicitation constitute a useful tool to achieve high phytoecdysteroid production in A. bracteosa.

\section{Conflicts of interest}

The authors declare no conflict of interest. 


\section{Acknowledgements}

Ecdysteroids standards were kindly provided by Prof. Josep CollToledano, Department of Biological Chemistry and Molecular Modeling, Spanish National Research Council (SNRC), Barcelona, Spain. This project was financed by the Higher Education Commission of Pakistan. Part of this work was financially supported by the Spanish MEC (BIO2014-51861-R) and the Generalitat de Catalunya (2014SGR215).

\section{References}

1 W. K. K. Barkatullah, M. Ibrar, A. Rauf, T. B. Hadda, M. S. Mubarak and S. Patel, J. Ethnopharmacol., 2015, 169, 335-346.

2 W. T. Hsieh, Y. T. Liu and W. C. Lin, J. Ethnopharmacol., 2011, 135, 116-125.

3 W. K. Kayani, E. Dilshad, T. Ahmed, H. Ismail and B. Mirza, BMC Complementary Altern. Med., 2016, 16, 375.

4 R. Gautam, S. M. Jachak and A. Saklani, J. Ethnopharmacol., 2011, 133, 928-930.

5 G. Kaithwas, R. Gautam, S. M. Jachak and A. Saklani, Asian Pac. J. Trop. Biomed., 2012, 2, 185-188.

6 A. Pal and R. S. Pawar, Int. J. Curr. Biol. Med. Sci., 2011, 1, 1214.

7 S. Chandel and U. Bagai, Parasitol. Res., 2011, 108, 801-805. 8 G. Fekete, L. A. Polgár, M. Báthori, J. Coll and B. Darvas, Pest Manage. Sci., 2004, 60, 1099-1104.

9 T. Otaka, M. Uchiyama, T. Takemoto and H. Hikino, Chem. Pharm. Bull., 1969, 17, 1352-1355.

10 V. N. Syrov, S. S. Nasyrova and Z. A. Khushbaktova, Eksp. Klin. Farmakol., 1996, 60, 41-44.

11 Z. Saatov, D. A. Agzamkhodzhaeva and V. N. Syrov, Chem. Nat. Compd., 1999, 35, 186-191.

12 V. N. Syrov and Z. A. Khushbaktova, Eksp. Klin. Farmakol., 2000, 64, 56-58.

13 D. S. Trenin and V. V. Volodin, Arch. Insect Biochem. Physiol., 1999, 41, 156-161.

14 A. I. Kuzmenko, E. Niki and N. Noguchi, J. Oleo Sci., 2001, 50, 497-506.

15 I. Mirzaev, V. N. Syrov, S. A. Khrushev and S. D. Iskanderova, Eksp. Klin. Farmakol., 1999, 63, 35-37.

16 W. Wang, T. Wang, W. Y. Feng, Z. Y. Wang, M. S. Cheng and Y. J. Wang, Neurosci. Res., 2014, 81, 21-29.

17 Q. Chen, Y. Xia and Z. Qiu, Life Sci., 2006, 78, 1108-1113.

18 A. G. Kurmukov and V. N. Syrov, Med. Zh. Uzb., 1988, 10, 68-70.

19 D. K. Najmutdinova and Z. Saatov, Arch. Insect Biochem. Physiol., 1999, 41, 144-147.

20 V. U. Ahmad, S. M. Khaliq-Uz-Zaman, M. Ali, S. Perveen and W. Ahmed, Fitoterapia, 1996, 67, 88-91.

21 L. Pistelli, A. Giovannini, B. Ruffoni, A. Bertoli and L. Pistelli, in Bio-Farms for Nutraceuticals, Springer, 2010, pp. 167-184.

22 M. D. Chilton, D. A. Tepfer, A. Petit, C. David, F. Cassedelbart and J. Tempe, Nature, 1982, 295, 432-434.

23 M.-D. Chilton, M. H. Drummond, D. J. Merlo, D. Sciaky, A. L. Montoya, M. P. Gordon and E. W. Nester, Cell, 1977, 11, 263-271.
24 F. Vilaine and F. Casse Delbart, Mol. Gen. Genet., 1987, 206, 17-23.

25 M. Cardarelli, D. Mariotti, M. Pomponi, L. Spano, I. Capone and P. Costantino, Mol. Gen. Genet., 1987, 209, 475-480.

26 A. D. Paolis, M. L. Mauro, M. Pomponi, M. Cardarelli, L. Spano and P. Costantino, Plasmid, 1985, 13, 1-7.

27 A. Mallol, R. M. Cusidò, J. Palazòn, M. Bonfill, C. Morales and M. T. Piñol, Phytochemistry, 2001, 57, 365-371.

28 E. Moyano, S. Fornalé, J. Palazón, R. M. Cusidó, M. Bonfill, C. Morales and M. T. Piñol, Phytochemistry, 1999, 52, 12871292.

29 T. Matsumoto and N. Tanaka, Agric. Biol. Chem., 1991, 55, 1019-1025.

30 N. Tanaka and T. Matsumoto, Plant Tissue Cult. Lett., 1993, 10, 78-83.

31 N. Tanaka and T. Matsumoto, Plant Cell Rep., 1993, 13, 8790.

32 O. T. Kim, M. Manickavasagm, Y. J. Kim, M. R. Jin, K. S. Kim, N. S. Seong and B. Hwang, J. Plant Biol., 2005, 48, 258-262.

33 I. R. Soriano, I. T. Riley, M. J. Potter and W. S. Bowers, J. Chem. Ecol., 2004, 30, 1885-1899.

34 W. K. Kayani, J. Palazòn, R. M. Cusidò and B. Mirza, RSC Adv., 2016, 6, 22700-22708.

35 R. U. Schenk and A. Hildebrandt, Can. J. Bot., 1972, 50, 199204.

36 T. Murashige and F. Skoog, Physiol. Plant., 1962, 15, 473-497.

37 J. J. Doyle and J. L. Doyle, Focus, 1990, 12, 13-15.

38 A. Castro, J. Coll, Y. A. Tandrón, A. K. Pant and C. S. Mathela, J. Nat. Prod., 2008, 71, 1294-1296.

39 J. J. Wu, K. W. Cheng, H. Wang, W. C. Ye, E. T. Li and M. Wang, Phytochem. Anal., 2009, 20, 58-63.

40 C. David, M.-D. Chilton and J. Tempé, Nat. Biotechnol., 1984, $2,73-76$.

41 O. Nilsson and O. Olsson, Physiol. Plant., 1997, 100, 463-473.

42 D. Bouchez and J. Tourneur, Plasmid, 1991, 25, 27-39.

43 R. O. Morris, Annu. Rev. Plant Physiol., 1986, 37, 509-538.

44 J. Palazón, T. Altabella, R. M. Cusidó, M. Ribó and M. T. Piñol, Biol. Plant., 1995, 37, 161-168.

45 K. H. Jung, S. S. Kwak, C. Y. Choi and J. R. Liu, Plant Cell Rep., 1995, 15, 51-54.

46 R. J. Robins, Nat. Prod. Rep., 1998, 15, 549-570.

47 V. Gaudin, T. Vrain and L. Jouanin, Plant Physiol. Biochem., 1994, 32, 11-29.

48 A. Bakrim, A. Maria, F. Sayah, R. Lafont and N. Takvorian, Plant Physiol. Biochem., 2008, 46, 844-854.

49 J. Chappell, Plant Physiol., 1995, 107, 1-6.

50 Q. J. Wang, L. P. Zheng, P. F. Zhao, Y. L. Zhao and J. W. Wang, Plant Physiol. Biochem., 2014, 84, 1-9.

51 Q. J. Wang, L. P. Zheng, Y. H. Sima, H. Y. Yuan and J. W. Wang, Plant Omics, 2013, 6, 116-120.

52 S. Mangas, M. Bonfill, L. Osuna, E. Moyano, J. Tortoriello, R. M. Cusidò, M. T. Piñol and J. Palazón, Phytochemistry, 2006, 67, 2041-2049.

53 D. M. Cheng, G. G. Yousef, M. H. Grace, R. B. Rogers, J. Gorelick-Feldman, I. Raskin and M. A. Lila, Plant Cell, Tissue Organ Cult., 2008, 93, 73-83. 